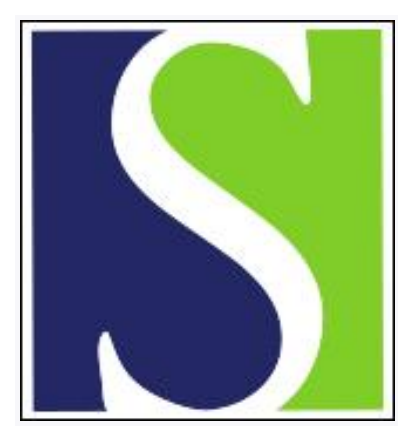

Scand J Work Environ Health 1983;9(2):89-93

https://doi.org/10.5271/sjweh.2418

Issue date: Apr 1983

Screening for occupational exposures and congenital malformations.

by Kurppa K, Holmberg PC, Hernberg S, Rantala K, Riala R, Nurminen $\mathrm{T}$

This article in PubMed: www.ncbi.nlm.nih.gov/pubmed/6648425

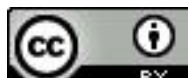

This work is licensed under a Creative Commons Attribution 4.0 International License 


\title{
Screening for occupational exposures and congenital malformations
}

\section{Preliminary results from a nationwide case-referent study}

\author{
by Kari Kurppa, MD, Peter C Holmberg, MD, Sven Hernberg, MD, \\ Kaarina Rantala, MSc(ChemEng), Riitta Riala, MSc(ChemEng), \\ Tuula Nurminen, MSc ${ }^{1}$
}

\begin{abstract}
KURPPA K, HOLMBERG PC, HERNBERG S, RANTALA K, RIALA R, NURMINEN T. Screening for occupational exposures and congenital malformations: Preliminary results from a nationwide case-referent study. Scand $j$ work environ health 9 (1983) 89-93. Since 1976 the Finnish matched-pair Register of Congenital Malformations has been linked to a special project which screens for associations between selected congenital malformations and chemical and physical exposures during early pregnany. Case mothers and their referents are personally interviewed. Exposure data are quantitated blindly by a team of industrial hygienists and occupational health experts. An analysis of data from 1,047 pairs is now underway. The pairs consist of 289 defects of the central nervous system, 421 orofacial clefts, 200 selected structural malformations of the skeleton, and 137 selected cardiovascular defects. Exposure to organic solvents was associated with defects of the central nervous system in the initial two-year material. However this association was no longer detectable during the following three-year period. More pairs must be gathered before a reasonable judgment regarding the teratogenic potential of solvents becomes possible.
\end{abstract}

Key terms: disinfectants, dysmorphogenesis, organic solvents.

The etiology of human developmental defects is mostly unclear (6). Known environmental causes (including infections) do not exceed $10 \%$ although this figure could be an underestimate. Some of the malformations of unknown etiology might be due to exposures at work. In most studies so far, attention to environmental causes has been focused mainly on drugs or various infectious diseases, recently also on smoking habits and alcohol and coffee consumption. Epidemiologic studies on occupational etiologies of malformations are scarce and often based on crude information. So far, evidence on exposures at worksites as contributors to teratogenesis is circumstancial at best.

1 Institute of Occupational Health, Helsinki, Finland

Reprint requests to: Dr $\mathrm{K}$ Kurppa, Haartmaninkatu 1, Institute of Occupational Health, Haartmaninkatu 1, SF-00290 Helsinki, Finland.
A register-based case-referent study on associations between congenital malformations and environmental exposures, particularly work-related, was started in Finland in 1976. This exploratory study at first focused on malformations of the central nervous system. The initial series showed an interesting cluster of case mothers that had been occupationally exposed to organic solvents (2). In 1978 the investigation was extended to include other selected malformation groups as well.

\section{Methods}

The primary data of the present study are derived from the records of the Finnish matched-pair Register of Congenital Malformations to which notification of all congenital defects detected during the first year of life has been compulsory since 1963 (5). 
Nested in the Register is another smaller register that consists of selected marker defects. This smaller register is specifically used for research purposes (5). Each mother selected for the special study is matched with a referent mother whose delivery immediately preceded that of the study mother in the same maternity welfare district. (Finland is divided into 1,329 districts with a central unit in each district.) Nonmatched modifying and confounding factors are considered in the data analysis. Validity aspects of the present approach have been previously discussed in detail (5). The pairs of mothers are routinely interviewed by means of standard register procedures. The retrieval rate of the questionnaires has been more than $99 \%$.

In the present study further information concerning various exposures related to occupational or leisure-time activities of the mothers is obtained through personal interviews (3). These thorough interviews are undertaken by two practiced interviewers from the Institute of Occupational Health, Helsinki. Exposure data are collected with a specially designed questionnaire. The personal interviews usually take place within two to four months after delivery and are conducted at the local maternity welfare center of the mother. More than $95 \%$ of the mothers have accepted participation in this special study.

The mother is first requested to describe her ordinary workday with different work phases in detail. The interview is thus not restricted as to particular hypotheses but registers exposures as they come from the mothers without attention to a priori biological meaningfulness of the exposure. Following this open question the interviewer requests, according to fixed rules, information on possible exposures to solvents, pesticides, decay-preventing agents, disinfectants, metals, and radiation. The open question usually reveals continuous exposures that have been more or less similar day to day, eg, styrene exposure in the reinforced plastics industry, whereas the fixed questions yield more accurate information on exposures of shorter duration, eg, $1 \mathrm{~d}$ of painting closets at home. If the mother reports a chemical exposure, the inter- viewer records the specific trademarks and brand names of the products as detailedly as the mother can recall. Chemicals used during leisure time (eg, home painting) are similarly recorded.

Two industrial hygienists use these questionnaire forms as their source for exposure estimation. The chemical composition of commercial products that appear in the answers by their tradenames is clarified. Further contacts with the manufacturers or importers are sometimes necessary to qualitate the exposure. This is not however a frequent problem as, according to new Finnish legislation, manufacturers and importers must provide users with a safety data sheet with detailed information on the hazardous ingredients of products.

During the analysis of exposure information the hygienists are unaware of whether the information comes from a case or from a referent mother. The categorization of the strength of the exposure (none/minor/substantial/strong) is largely based on the industrial hygienic expertise of the Institute of Occupational Health, Helsinki. Hygienic measurements of the quantity of individual exposures are usually not available. Yet, if a mother has worked in a big or middle-sized factory, a quantitative estimate of the exposure can often be made from the files on hygienic measurements undertaken by the regional institute of occupational health in that area. When necessary, the hygienist requests further information on exposures through personal contacts with employers and may visit the workplaces.

After the primary estimation of the exposure data, the hygienists classify the material, still blindly, together with two experts in occupational medicine, into the final exposure categories. For example, mothers are considered "substantially" exposed to organic solvents if their estimated exposure has reached approximately one-third of the current threshold limit value of the American Conference of Governmental Industrial Hygienists or if the estimated peak exposure had reached the threshold limit concentration, eg, during home painting in confined spaces. Thereafter the codes are broken, and the exposure frequencies are statistically tested. For the time being, only exposures 
which have occurred during the first trimester of pregnancy are included in the analysis.

\section{Preliminary results and comments}

Current case-referent distributions of pairs exposed to solvents are given in table 1. Included are solvent mixtures which contain mainly aliphatic hydrocarbons (such as lacquer petrol, white spirit), aromatic hydrocarbons (styrene, xylene, toluene, benzene), and chlorinated hydrocarbons (dichloromethane, trichloroethylene, perchloroethylene). Central nervous system malformations and oral clefts suggest interesting though not strong associations. It is important to bear in mind that the multiple-comparison situation in the present study is bound to produce some statistical associations in the present material, even if no meaningful associations existed in reality.

Exposure to organic solvents was associated with central nervous system defects for the first two-year material (2), which indicated that 14 case and 3 referent mothers had been exposed to solvents in early pregnancy. For the following threeyear period the respective distribution was $6 / 6$, indicating no association. In an attempt to study this discrepancy, the initial two-year material was blindly reanalyzed by industrial hygienists not involved before. The renanalysis showed an outcome materially similar to the one originally reported (2). A possible explanation for the disappearence of the association might be that chance (multiple-comparison situation) has been responsible for the initial relation. There is another possibility however. Occupational health activities expanded in Finland during the latter part of the 1970s, in the midst of the present study. It was recommended that pregnant women should not be exposed to chemicals. The frequency of substantial exposure to organic solvents during pregnancy seems to have declined in the course of the present study. Nowadays we encounter only rare cases of exposure strengths as high as found earlier (2).

An increased malformation rate has been reported for hospital personnel exposed to hexachlorophene (1). Our material so far includes 140 discordant pairs that have been exposed to disinfectants in hospitals or the like (fig 1 ). The casereferent distribution was $33 / 44$ for the discordant pairs exposed to hand washing agents (chlorhexidine, hexachlorophene, iodine-containing agents, etc) and $51 / 55$ for the discordant pairs exposed to surface disinfectants (ampholytic compounds, chlorine, chlorhexidine, halocarbane, phenols, quaternary ammonium compounds, etc). Six case mothers and six referents had been exposed to hexachlorophene.

Table 2 shows preliminary distributions of some other exposure categories. These figures are subject to changes since final decisions regarding some individual exposures have not yet been made at our exposure meetings. Nonionizing radiation in table 2 refers mainly to restaurant

Table 1. Exposure to organic solvents during early pregnancy — An analysis of 1,047 pairs.

\begin{tabular}{lrc}
\hline Malformation & Case & Referent \\
\hline Central nervous system defects & 20 & 9 \\
Oral clefts & 15 & 5 \\
Skeletal defects & 5 & 3 \\
Cardiovascular defects & 3 & 3 \\
\hline Total & 43 & 20 \\
\hline
\end{tabular}

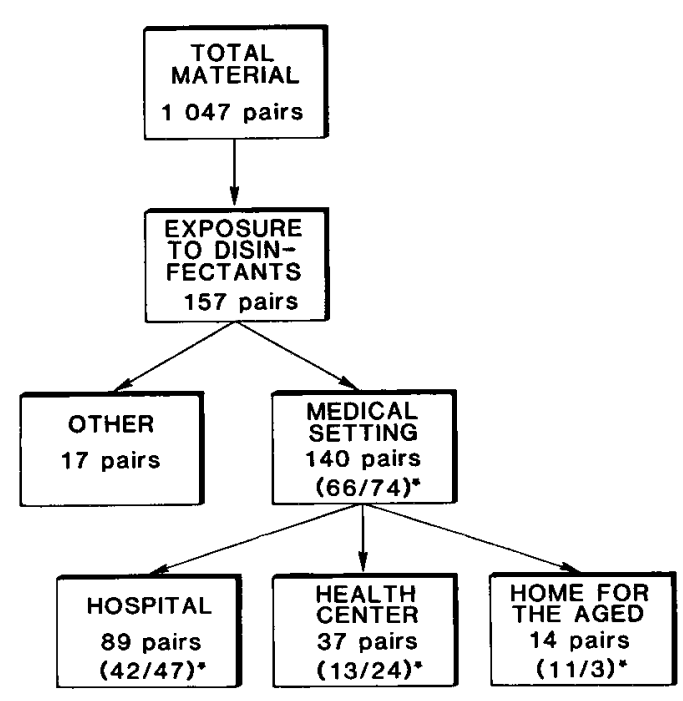

* CAse/REFERENT RATIo

Fig 1. Exposure to disinfectants. 
Table 2. Distributions of "substantially" exposed discordant pairs. (The distributions are preliminary and subject to change in the course of a more-detailed quantitation of the exposures.)

\begin{tabular}{|c|c|c|c|c|c|c|c|c|c|c|}
\hline \multirow[t]{2}{*}{ Exposure } & \multicolumn{2}{|c|}{$\begin{array}{c}\text { Central ner- } \\
\text { vous system } \\
\text { defects } \\
(N=289) \\
\end{array}$} & \multicolumn{2}{|c|}{$\begin{array}{c}\text { Oral } \\
\text { clefts } \\
(\mathrm{N}=421)\end{array}$} & \multicolumn{2}{|c|}{$\begin{array}{c}\begin{array}{c}\text { Skeletal } \\
\text { defects }\end{array} \\
(\mathrm{N}=200)\end{array}$} & \multicolumn{2}{|c|}{$\begin{array}{c}\text { Cardio- } \\
\text { vascular } \\
\text { defects } \\
(N=137)\end{array}$} & \multicolumn{2}{|c|}{$\begin{array}{c}\text { Total } \\
(\mathrm{N}=1,047)\end{array}$} \\
\hline & Case & $\begin{array}{c}\text { Refer- } \\
\text { ent }\end{array}$ & Case & $\begin{array}{l}\text { Refer- } \\
\text { ent }\end{array}$ & Case & $\begin{array}{c}\text { Refer- } \\
\text { ent }\end{array}$ & Case & $\begin{array}{l}\text { Refer- } \\
\text { ent }\end{array}$ & Case & $\begin{array}{c}\text { Refer- } \\
\text { ent }\end{array}$ \\
\hline $\begin{array}{l}\text { Anesthetic gases } \\
\text { Disinfectants } \\
\text { Hand washing }\end{array}$ & 1 & 3 & 1 & 1 & - & - & - & 1 & 2 & 5 \\
\hline $\begin{array}{l}\text { agents } \\
\text { Surface }\end{array}$ & 5 & 3 & 21 & 29 & 2 & 6 & 5 & 6 & 33 & 44 \\
\hline $\begin{array}{l}\text { disinfectants } \\
\text { Ionizing radiation }\end{array}$ & $\begin{array}{r}10 \\
8\end{array}$ & 4 & 28 & 33 & 8 & $\begin{array}{r}12 \\
6\end{array}$ & $\begin{array}{l}5 \\
5\end{array}$ & $\begin{array}{l}6 \\
3\end{array}$ & 51 & 55 \\
\hline Nonionizing radiation & 5 & $\begin{array}{l}4 \\
5\end{array}$ & $\begin{array}{l}13 \\
10\end{array}$ & $\begin{array}{r}10 \\
8\end{array}$ & $\begin{array}{l}4 \\
7\end{array}$ & $\begin{array}{l}6 \\
7\end{array}$ & $\begin{array}{l}5 \\
4\end{array}$ & 4 & 26 & $\begin{array}{l}23 \\
24\end{array}$ \\
\hline Noise & 19 & 19 & 18 & 10 & 12 & 8 & 7 & 4 & 56 & 41 \\
\hline Pesticides & 1 & 1 & 5 & 1 & - & 1 & 1 & 2 & 7 & 5 \\
\hline Antineoplastic drugs & 1 & - & 2 & 2 & 2 & - & 1 & - & 6 & 2 \\
\hline Pharmaceutical dust & 1 & 1 & 2 & - & - & 1 & - & - & 3 & 2 \\
\hline Metals & 1 & 2 & 8 & 4 & 1 & 3 & - & - & 10 & 9 \\
\hline $\begin{array}{l}\text { Textile dust } \\
\text { Fur dust }\end{array}$ & 6 & 8 & 21 & 16 & 8 & 9 & 8 & 2 & 43 & 35 \\
\hline Fur dust & 4 & - & 1 & - & - & 2 & - & - & 5 & 2 \\
\hline
\end{tabular}

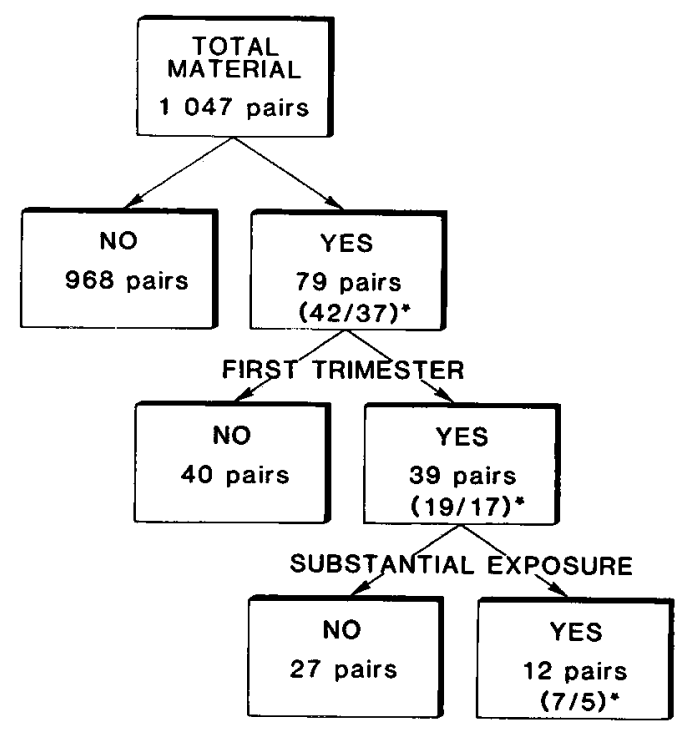

- CASE/REFERENT RATIO

Fig 2. Exposure to pesticides.

personnel working with microwave ovens, but also to physiotherapists that use radiofrequency diathermy appliances. Most mothers in the "metal" group are dental nurses that have handled mercury at work. The mothers exposed to noise have been exposed at a noise level of about $82 \mathrm{~dB}(\mathrm{~A})$ or more.
We think that it is hard to miss many of the substantial exposures with the present method. The special interviews yield detailed information on exposures. A major problem is that only a small fraction of pregnant Finnish women is nowadays substantially exposed to any specific group of chemicals. Take for instance the possibility that an exposure to pesticides, a heterogeneous group of chemicals, would indeed result in an increased occurrence of malformations. Detailed data collection may have lasted for years. Yet the study may end up with too small a number of pairs (individual exposures) to allow for a meaningful statistical analysis (fig 2). The study cannot answer the scientifically important question of whether or not a certain exposure (eg, individual pesticides) is teratogenic in humans. Yet the result might imply, with due precautions, that that particular type of exposure probably does not present a serious teratogenic risk in the current Finnish society. The latter argument may prove valid for some environmental exposures. In any case it is probably impossible to prove with an epidemiologic approach that a chemical that passes the placenta and has biological activity is not teratogenic. 
In 1978 there were approximately 60,000 births in Finland, and the Register was notified of about 1,000 congenital defects, including minor malformations. This situation could mean that at least $85 \%$ of the estimated true occurrence of malformations detectable at birth, approximately $2 \%$ in Finland (4), were registered. The percentage is higher for the major malformations. Virtually all cases of some groups (eg, anencephalus, oral clefts) will be reported. At least in the case of these specific malformation groups it is possible to consider the data coming from a nationwide dynamic population consisting of all pregnancies that end up with the birth of a live or dead child. If a markedly enhanced risk for these major defects exists in Finland for any specified chemical or occupational group (laboratory personnel, nurses, etc), we should be able to detect this hazard. On the other hand we only study those malformations which are considered to have the most reliable diagnosis and notification. Thus our study does not yield information concerning minor defects or other adverse outcomes related to possible dysmorphogenesis.

\section{Acknowledgments}

We are indebted to Ms T Suomela and Ms $\mathrm{R}$ Vesanto for their technical assistance and to the Finnish Work Environment Fund for their financial support.

\section{References}

1. Halling $H$. Suspected link between exposure to hexachlorophene and malformed infants. Ann ny acad sci 320 (1979) 426-435.

2. Holmberg PC. Central nervous system defects in children born to mothers exposed to organic solvents during pregnancy: A case-control study. Lancet 2 (1979) $177-179$.

3. Holmberg PC, Kurppa K. An epidemiologic approach to the study of possible teratogenic effects of chemical and physical environments. Scand $j$ work environ health 8 (1982): suppl $1,89-91$.

4. Saxén L, Härö S. Vastasyntyneiden epämuodostumat Suomessa [Congenital malformations of newborns in Finland]. Duodecim (Helsinki) 80 (1964) 257-263.

5. Saxén L, Klemetti A, Härö AS. A matchedpair register for studies of selected congenital defects. Am j epidemiol 100 (1974) 297-306.

6. Wilson JG. Environment and birth defects. Academic Press, Inc, New York, NY 1974. $305 \mathrm{p}$. 